\title{
Perception and correlates of excessive vaginal discharge in rural women
}

\author{
Sheena A. Mammen ${ }^{1 *}$, Shavinder Singh ${ }^{1}$, Isaac Rajesh ${ }^{1}$, Sunita Goyal ${ }^{2}$
}

\begin{abstract}
${ }^{1}$ Department of Community Medicine, ${ }^{2}$ Department of Obstetrics and Gynecology, Christian Medical College,
\end{abstract} Ludhiana, Punjab, India

Received: 27 May 2017

Accepted: 27 June 2017

\section{*Correspondence:}

Dr. Sheena A. Mammen,

E-mail: sheena.mammen@gmail.com

Copyright: () the author(s), publisher and licensee Medip Academy. This is an open-access article distributed under the terms of the Creative Commons Attribution Non-Commercial License, which permits unrestricted non-commercial use, distribution, and reproduction in any medium, provided the original work is properly cited.

\begin{abstract}
Background: Vaginal discharge is one of the most common symptoms of gynecological morbidity. Vaginitis is the most prevalent cause. Gynecological disorders have substantial impact on female health and behaviour. Recent evidence suggests that the association between the complaint of vaginal discharge and the presence of Reproductive Tract Infections is weak. Women who are overanxious, introspective or suffering from fears of venereal disease and cancer tend to exaggerate the complaint of vaginal discharge into something pathological. The objective of the study was to study rural women's perception and health care seeking behaviour regarding excessive vaginal discharge. To study various psychological and biological correlates of excessive vaginal discharge

Methods: This was a community based cross sectional study, conducted in the rural field practice areas under the Department of Community Medicine, Christian Medical College, Ludhiana. House to house surveys were conducted with semi-structured questionnaire and GAD 7 (Generalised Anxiety Disorder) scale, using systematic random sampling.

Results: 160 rural women were interviewed to collect data. Of them, $27.5 \%$ reported having excessive vaginal discharge. There was no association observed between menstrual hygiene methods and excessive vaginal discharge $(\mathrm{p}=0.77)$. Association couldn't be observed with selection of barrier and other non-barrier methods of contraception $(p=0.09)$ either. Statistically significant association was observed between presence of anxiety and vaginal discharge $(\mathrm{p}=0.01)$.

Conclusions: All vaginal discharges are not pathological. Causative factor of excessive vaginal discharge may not be infections always. There was a statistically significant association between anxiety and perceived vaginal discharge.
\end{abstract}

Keywords: Health care seeking behavior, Prevalence, Rural women, Vaginal discharge

\section{INTRODUCTION}

Reproductive tract infections (RTIs) including sexually transmitted infections (STIs) present a huge burden of disease and adversely impact reproductive health. They cause suffering for both men and women around the world, but their consequences are far more devastating and widespread among women. These infections often go undiagnosed and untreated, and lead to complications such as infertility, ectopic pregnancy and cervical cancer.
Pelvic inflammatory disease arising from STIs poses a major public health problem and adversely affects the reproductive health of poor and untreated women. ${ }^{1}$

The complaint of abnormal vaginal discharge is very common. ${ }^{2}$ Vaginal discharge is one of the most common symptoms of gynaecological morbidity. ${ }^{3}$ The amount of vaginal discharge ordinarily present in the adult is that the introitus feels comfortably moist but there is not enough to stain the underclothing. However vaginal 
secretions also increase physiologically at the time of ovulation, a few days just before menstruation, during pregnancy and during sexual excitement. Leucorrhoea means an excessive amount of normal vaginal discharge, but it never causes pruritus and is never offensive. An excessive degree of vaginal secretion is not necessarily pathologically infected, but could be hormonal. ${ }^{4}$ WHO has defined vaginal discharge syndrome as abnormal vaginal discharge (amount, colour, and odour) with or without lower abdominal pain or specific symptoms or specific risk factors. ${ }^{5}$ Vaginitis is the most prevalent cause of excessive vaginal discharge, followed by cervicitis. $^{6}$

The World Health Organization has recommended syndromic management, in which women complaining of vaginal discharge are treated for some or all of the five common reproductive tract infections: Chlamydia trachomatis infection, gonorrhea, and trichomoniasis, which are sexually transmitted infections and bacterial vaginosis and candidiasis, which result from disturbance in the normal bacterial flora of vagina. ${ }^{7}$

However, recent evidence suggests that the association between the complaint of vaginal discharge and the presence of RTIs (Reproductive Tract Infections) is weak. $^{2}$ Thus, studies in clinical settings in Bangladesh and India reported that only 30 and $60 \%$ of women complaining of vaginal discharge had a laboratory confirmed RTI. ${ }^{8,9}$ Despite the poor correlation between RTIs and vaginal discharge, the syndromic approach remains the cornerstone of intervention programmes for women's reproductive health, mainly due to lack of evidence supporting alternative aetiologies for the complaint. $^{2}$

The complaint of vaginal discharge depends very much on the ideas, powers of observation and fastidiousness of individual women. Women who are overanxious, introspective, or suffering from fears of venereal disease and cancer tend to exaggerate this in to something pathological. $^{4}$

A study done in Goa shows that psychosocial factors, notably the presence of a Common Mental Disorder (CMD) or symptoms of somatoform disorders, are the factors most strongly associated with the complaint of vaginal discharge; there was little association of the complaint with RTI. ${ }^{2}$ Leucorrhoea is one of the major problems among the reproductive age group women. It is important because besides being a source of constant distress to the female it may sometimes be the earliest manifestation of some of the major gynaecological disease. Gynaecological disorders have substantial impact on female reproductive ability, mental health, and ability to work and to perform routine physical activities. ${ }^{10}$

The estimated prevalence of abnormal vaginal discharge has been varying in various studies. A study done in three villages in Haryana showed prevalence of $28.7 \%$ of abnormal vaginal discharge, while a study done in an urban slum in Delhi showed prevalence of $32.7 \% .^{11,12} \mathrm{~A}$ study done in Goa showed that prevalence of abnormal vaginal discharge was $14.5 \% .^{2}$

Though many studies have been done to estimate the prevalence and the various causes of vaginal discharge, not much data is available regarding what women know about vaginal discharge, their attitudes, health care seeking behaviour and the various correlates regarding the same in rural setting. With this background, we conducted this study in our rural field practice areas in Ludhiana.

The objective of the study was to study rural women's knowledge, attitudes and health care seeking behaviour regarding excessive vaginal discharge. To study various psychological and biological correlates of excessive vaginal discharge

\section{METHODS}

This was a community based Cross-sectional study using a semi-structured questionnaire. The General Anxiety Disorder (GAD) 7 scale was also be used to assess level of anxiety in the individual. This is a validated scale and is extensively used in research. ${ }^{13}$

The study was conducted among women of reproductive age group, residing in Lalton Kalan, Lalton Khurd, Daad and Dolon villages in Punjab which are field practice areas under the Community Medicine department in Christian Medical College, Ludhiana. The department maintains a list of the eligible couples residing in the field practice areas. The study subjects were selected from the eligible couple list using systematic random sampling. House to house interviews were conducted after obtaining the informed consent from the respondents. The sample size was calculated to be 144 , taking prevalence of abnormal vaginal discharge as $28 \%,{ }^{11}$ the total population of eligible couples being $15 \%$ of the population which is 1500. An additional 10\% was selected for off-setting non-response, bringing the total sample size to 160 . This was calculated using Openepi software.

\section{Inclusion criteria}

- Married women up to the age of menopause.

\section{Exclusion criteria}

- Unmarried women

- Pregnant women

- Women in puerperal period

\section{Statistical analysis}

Data was entered using classical Epidata entry software. Data was analysed using Epidata Analysis Version 2.2.2 
and EpiInfo 7 softwares. Percentages and 95\% confidence intervals are calculated for categorical data. Mean and standard deviations and $95 \%$ confidence intervals were calculated for continuous variables. Data was analysed by proportions, Chi square test, Fisher's exact test and logistic regression.

\section{RESULTS}

A total of 160 study subjects were interviewed. The mean age of respondents was $34.71( \pm 6.83)$ years. Majority $(26.3 \%)$ of respondents were in the age group of 35- 40 . Majority of the respondents $(97.5 \%)$ were married at time of the interview. Only $11.9 \%$ of respondents were illiterate. Majority of the respondents (26.9\%) had secondary education. Only $12.5 \%$ of the respondents were employed. Rest of the $87.5 \%$ respondents were home makers. Majority $(40.6 \%)$ belonged to Class IV socioeconomic class according to Modified BG Prasad Socioeconomic Classification.

Out of the 160 women, four were nulliparous. Majority $(43.8 \%)$ of them had parity of two. Among the respondents, $70.6 \%$ never had any history of abortions. Forty five percent of the respondents were not using any contraceptive methods. Barrier method of contraception was used only by $18.8 \%$ of the respondents. IUCD was used only by 9 respondents. Sanitary pads were used by $55 \%$ of respondents and $45 \%$ of them were using clothes as menstrual hygiene method (Table 1).

Table 1: Perceived excessive vaginal discharge based on various attributes.

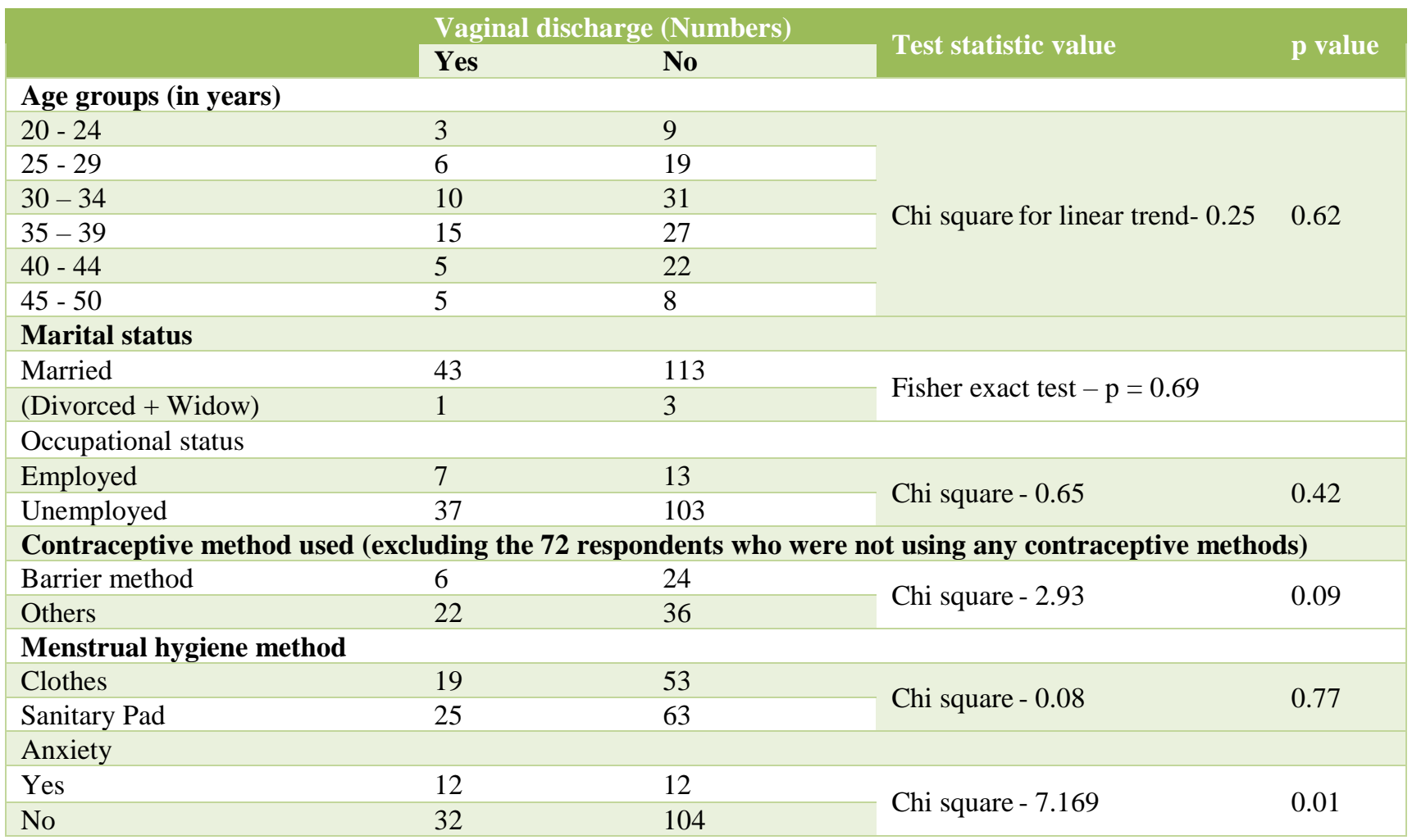

The prevalence of excessive vaginal discharge was found to be $27.5 \%$. Multiple reasons were given by the respondents for perceiving excessive vaginal discharge, of which the most common reason being 'the discharge wets the clothes' $(77.2 \%)$, followed by 'the discharge being thick' $(22.7 \%)$. Some respondents $(9.1 \%)$ attributed it to feeling of weakness. Out of the 44 respondents with history of excessive vaginal discharge, $77.3 \%$ had history of other associated symptoms along with the vaginal discharge. The most common associated symptom were pruritus vulvae $(58.8 \%)$ and backache $(58.8 \%)$ followed by lower abdominal pain $(55.9 \%)$. Of the 44 respondents with history of excessive vaginal discharge, $47.7 \%$ respondents did not know the cause of excessive vaginal discharge. Most common perceived cause was weakness $(27.3 \%)$, followed by infections $(9.1 \%)$, hot foods $(9.1 \%)$ and excessive body heat $(4.5 \%)$.

Among the 44 respondents with history of excessive vaginal discharge, $75 \%$ took treatment for the same. Of them, $84.8 \%$ consulted doctors for the treatment. Only 4 respondents consulted traditional practitioners and one respondent consulted health worker. Of the 160 respondents, $136(85 \%)$ had anxiety, according to the 
GAD 7 questionnaire. No statistically significant association was observed between excessive vaginal discharge and parity $(\mathrm{p}=0.78)$ or number of abortions $(\mathrm{p}=0.83)$.

Univariate analysis showed statistically significant association between presence of anxiety and vaginal discharge $(\mathrm{p}=0.01)$. Statistically significant linear trend was observed between educational status and consultation rate $(\mathrm{p}=0.04)$ and also consulting qualified doctors $(p=0.04)$ for excessive vaginal discharge. Multivariate analysis showed statistically significant association between educational status $(0.015)$ and presence of anxiety (0.006) with perceived excessive vaginal discharge.

\section{DISCUSSION}

Of the 160 women interviewed, 44 (27.5\%) had history of excessive vaginal discharge. This was comparable to the prevalence observed in a community based crosssectional study done in Haryana by Singh A, where the prevalence of vaginal discharge was estimated to be $28.7 \% .^{11}$ Similar results were observed in a study done in an urban slum in Delhi by Kaur and Kapoor where the prevalence of leucorrhoea was $33 \% .^{12}$

Respondents, who gave history of excessive vaginal discharge, were asked the reason for perceiving excessive vaginal discharge. Multiple reasons were given by the respondents. The most common reason being 'discharge wets the clothes' $(77.2 \%)$, followed by the 'discharge being thick' $(22.7 \%)$. Some respondents $(9.1 \%)$ attributed it to feeling of weakness. Presence of foul smelling discharge $(13.6 \%)$ and itching in vulva $(9.1 \%)$ were also perceived as excessive vaginal discharge. While in a study done by Singh A in Haryana, all the cases reported wetting of undergarments. Foul smelling discharge was reported by $65.1 \%$ women. Consistency of discharge was told to be thick $(34.8 \%)$, thin $(40.9 \%)$ or mixed $(24.2 \%) .{ }^{11}$ While study done by Patel V et al. showed that $38.2 \%$ of women with vaginal discharge reported wetting of undergarments and more than half of the women with vaginal discharge told that the discharge is odourless. ${ }^{2}$ This difference can be because, in our study, the respondents were not specifically asked regarding the nature of discharge. Also, there is a wide range in the difference in perception regarding nature of excessive vaginal discharge.

Out of the 44 respondents with history of excessive vaginal discharge, $34(77.3 \%)$ of them had history of other associated symptoms along with the vaginal discharge. Multiple symptoms were reported by some respondents. The most common associated symptoms were pruritus vulvae $(58.8 \%)$ and backache $(58.8 \%)$ followed by lower abdominal pain (55.9\%). Dysmenorrhoea $(41.1 \%)$ and burning micturition $(38.2 \%)$ were other associated symptoms. Menstrual irregularities including oligomenorrhoea $(14.7 \%)$, menorrhagia $(8.8 \%)$ and polymenorrhoea $(2.9 \%)$ were also reported. No one had history of genital ulcers or fever. Similarly, Patel V et al. reported that $60 \%$ of women had associated symptoms with vaginal discharge. Among them itching in genital area was reported by $14.7 \%$, lower abdominal pain by $14 \%$, burning micturition by $9.4 \%$ and genital sore by $3.6 \%$. $^{2}$ The presence of other gynaecological symptoms suggests the presence of RTIs.

Out of the 44 respondents with history of excessive vaginal discharge, $21(47.7 \%)$ respondents told that they do not know the cause of excessive vaginal discharge. Most common perceived cause was weakness (27.3\%). Only 2 respondents told that it can be sexually transmitted. Other common perceived causes of excessive vaginal discharge include infections $(9.1 \%)$, hot foods $(9.1 \%)$ and excessive body heat $(4.5 \%)$. Mental tension was perceived as the cause by only one respondent. No one reported evil eye or hormonal abnormality as the cause, as found in other studies. Similar causes, were reported by studies in Delhi, Goa and Haryana, though the proportion of different perceived causes were different. $^{2,11,12}$ This showed a lack of awareness among rural women regarding the causes of abnormal vaginal discharge. Of the 160 respondents $136(85 \%)$ of them had anxiety. Similarly, study done in Goa reported high CMD and somatoform disorder symptom scores in women. ${ }^{2}$

Statistically significant association was found between presence of vaginal discharge and educational status of respondents $(\mathrm{p}=0.015)$ on multivariate analysis. Also, statistically significant linear trend was observed between educational status and consultation for vaginal discharge $(\mathrm{p}=0.04)$ and whether they consulted qualified doctor for the treatment $(\mathrm{p}=0.04)$ on univariate analysis. So, women who were literate could identify and report the problem of vaginal discharge more often than women who are illiterate. And the health care seeking behaviour of educated women was better.

No statistically significant trend was observed, when analyzed for any association between parity and history of vaginal discharge $(\mathrm{p}=0.78)$. But Kulkarni $\mathrm{R}$ and Durge $P$ reported a statistically significant association between high parity and leucorrhoea. ${ }^{10}$ When analyzed for any association of vaginal discharge with number of abortions in the respondents, no trend was observed with increase in number of abortions $(\mathrm{p}=0.83)$. While Pant $\mathrm{B}$ et al. reported statistically significant association between RTI and history of abortions. ${ }^{14}$

This study showed that almost $1 / 4^{\text {th }}$ of women in a rural community suffer from the complaint of excessive vaginal discharge. But the consultation rate for the complaint still remains low. The consultation rate for the complaint of vaginal discharge improves with better educational status. Also, better educated women tend to consult qualified doctors than traditional practitioners or health workers. All vaginal discharges need not be pathological. Causative factor of excessive vaginal 
discharge may not be infections always. There is a statistically significant association between anxiety and perceived excessive vaginal discharge.

\section{ACKNOWLEDGMENTS}

Authors would like to thank the entire faculty in the Department of Community Medicine, CMC Ludhiana, for all their support at different stages of this study. Author extend sincere thanks to our field staffs for their untiring support and cooperation during this study. Author would like to thank colleagues for their constant encouragement. Author taking this opportunity to thank the participants of study, who, beyond the barriers of a traditional society, came forward to share their views and answer the questionnaire.

Funding: No funding sources

Conflict of interest: None declared

Ethical approval: The study was approved by the Institutional Ethics Committee

\section{REFERENCES}

1. India. Ministry of Health and Family Welfare. National guidelines on prevention, management and control of reproductive tract infections including sexually transmitted infections [Internet]. New Delhi; 2007 [cited 2016 Oct 16]. Available from: http://www.ilo.org/wcmsp5/groups/public/ed_protect /protrav/ilo_aids/documents/legaldocument/wcms_1 17313.pdf.

2. Patel V, Pednekar S, Weiss H, Rodrigues M, Barros $\mathrm{P}$, Nayak B, et al. Why do women complain of vaginal discharge? A population survey of infectious and pyschosocial risk factors in a South Asian community. Int J Epidemiol. 2005;34(4):853-62.

3. Brabin L, Kemp J, Obunge OK, Ikimalo J, Dollimore $\mathrm{N}$, Odu NN, et al. Reproductive tract infections and abortion among adolescent girls in rural Nigeria. Lancet. 1995;345(8945):300-4.

4. Kumar. Jeffcoate's Principles of Gynaecology. 7th ed. New Delhi: Jaypee Brothers Medical Publishers; 2008.

5. World Health Organization Liberia Mission [Internet]. WHO; 2003. Available from: www.who.int/disasters/repo/ 11229.pdf.
6. World Bank. World Development Report 1993 : Investing in Health [Internet]. New York; 1993 Available https://openknowledge.worldbank.org/ handle /10986/5976.

7. World Health Organization. Management of sexually transmitted diseases. Geneva; WHO; 1994. Available from:

http://whqlibdoc.who.int/hq/1997/WHO_GPA_TEM _94.1_Rev.1.pdf.

8. Hawkes S, Morison L, Foster S, Gausia K, Chakraborty J, Peeling RW, et al. Reproductive-tract infections in women in low-income, low-prevalence situations: assessment of syndromic management in Matlab, Bangladesh. Lancet. 1999;20;354(9192):1776-81.

9. Vishwanath S, Talwar V, Prasad R, Coyaji K, Elias CJ, de Zoysa I. Syndromic management of vaginal discharge among women in a reproductive health clinic in India. Sex Transm Infect. 2000;76(4):303-6.

10. Kulkarni RN, Durge PM. A study of leucorrhoea in reproductive age group women of Nagpur City. Indian J Public Health. 2005;49(4):238-9.

11. Singh AJ. Vaginal discharge: Its causes and associated symptoms as perceived by rural north Indian women. Indian $\mathrm{J}$ Community Med. 2007;32:22-6.

12. Kaur J, Kapoor A. Perceptions and knowledge about leukorrhea in a slum dwelling South Asian community. J Family Reprod Health. 2014;8(1):4552.

13. Spitzer RL, Kroenke K, Williams JBW, Löwe B. A brief measure for assessing generalized anxiety disorder: the GAD-7. Arch Intern Med. 2006;22;166(10):1092-7.

14. Pant B, Singh JV, Bhatnagar M, Garg SK, Chopra H, Bajpai SK. Obstetric history and reproductive tract infections among married female (15-44 yrs.) in rural area of district Meerut, U.P. Indian J Public Health. 2006;50(1):60-1.

Cite this article as: Mammen SA, Singh S, Rajesh I, Goyal S. Perception and correlates of excessive vaginal discharge in rural women. Int J Reprod Contracept Obstet Gynecol 2017;6:3502-6. 